\title{
Masson's tumor of the kidney: a case report
}

\author{
Mohamed Ali Essid ${ }^{1 *}$ (D), Abderrazak Bouzouita', Ahlem Blel², Maroua Gharbi ${ }^{1}$, Marouen Chakroun?', \\ Aycha Ben Miled ${ }^{3}$, Haroun Ayed ${ }^{1}$, Mohamed Cherif ${ }^{1}$, Mohamed Riadh Ben Slama', Amine Derouiche ${ }^{1}$ \\ and Mohamed Chebil ${ }^{1}$
}

\begin{abstract}
Background: Intravascular papillary endothelial hyperplasia (known also as Masson's tumor) is a benign vascular lesion that commonly occurs in the skin and is rarely found in solid organs, especially in the kidney. In what follows, we will look into the first case of an unexpectedly diagnosed Masson's tumor of the kidney presenting as a suspicious renal cyst.

Case presentation: A 61-year-old Arab man presented with a left renal cyst, incidentally revealed by ultrasonography. The laboratory values were unremarkable. Computed tomography and magnetic resonance imaging demonstrated a $38 \mathrm{~mm}$ left renal midportion Bosniak IV cyst. Our patient underwent a radical nephrectomy. Histopathology revealed the diagnosis of intravascular papillary endothelial hyperplasia. There was no recurrence detected after 9 years of follow-up.
\end{abstract}

Conclusions: Renal intravascular papillary endothelial hyperplasia is a rare benign tumor which can mimic a suspicious renal mass on radiological findings. Thus, this entity should be considered more often in the thick of the diagnostic possibilities in order to avoid unnecessary nephrectomies.

Keywords: Bosniak classification, Intravascular papillary endothelial hyperplasia, Kidney, Masson's tumor, Nephrectomy, Renal cyst

\section{Background}

Intravascular papillary endothelial hyperplasia (IPEH) is a benign vascular lesion commonly known as Masson's tumor, which was first described in 1923 by Masson. IPEH is a reactive process of endothelial proliferation that takes place around thrombi in the setting of venous stasis.

This pathology occurs more often in the extremities of the body on cutaneous tissues. Only 12 cases of this tumor localized in the kidney have been described in the literature (Table 1). In this article, we report the first case in which this tumor presents as a suspicious renal cyst. We aimed to provide further insight about this rare entity to better characterize it, in order to avoid some unnecessary nephrectomies.

\footnotetext{
* Correspondence: docdali86@gmail.com

1 Department of Urology, Charles Nicolle University Hospital of Tunis,

Boulevard du 9 Avril 1938, 1006 Tunis, Tunisia

Full list of author information is available at the end of the article
}

\section{Case presentation}

We describe a 61-year-old Arab man who retired from teaching 2 years ago. He did not smoke tobacco or consume alcohol. His past medical history included two surgical operations: a hydatid cyst of the liver operated on 6 years ago in a surgery department and a right ureteral lithiasis operated on in our urology department 4 years ago (at that time, he had only been explored by an intravenous pyelogram). He had been under alpha blocker for benign prostatic hyperplasia for 6 months. He was admitted for a suspicious renal cyst, incidentally found on renal and vesicoprostatic ultrasound. He had no complaints. His physical examination was unremarkable. His temperature was $37.2{ }^{\circ} \mathrm{C}$, his blood pressure was $134 / 82 \mathrm{mmHg}$, and his pulse rate was regular at 74 beats per minute. On laboratory values, white blood cell count was $7.9 \times 10^{3} / \mathrm{mL}$, red blood cell count $4.1 \times 10^{6} / \mathrm{mL}$, hemoglobin $14.2 \mathrm{~g} / \mathrm{dL}$, platelets $396 \times 10^{3} / \mathrm{mL}$, creatinine $1.04 \mathrm{mg} / \mathrm{dL}$, sodium $138 \mathrm{mEq} / \mathrm{L}$, potassium $4.1 \mathrm{mEq} / \mathrm{L}$, and C-reactive protein $1 \mathrm{mg} / \mathrm{L}$. Urines examination showed no leukocyturia or bacteriuria.

(c) The Author(s). 2018 Open Access This article is distributed under the terms of the Creative Commons Attribution 4.0 International License (http://creativecommons.org/licenses/by/4.0/), which permits unrestricted use, distribution, and reproduction in any medium, provided you give appropriate credit to the original author(s) and the source, provide a link to the Creative Commons license, and indicate if changes were made. The Creative Commons Public Domain Dedication waiver (http://creativecommons.org/publicdomain/zero/1.0/) applies to the data made available in this article, unless otherwise stated. 


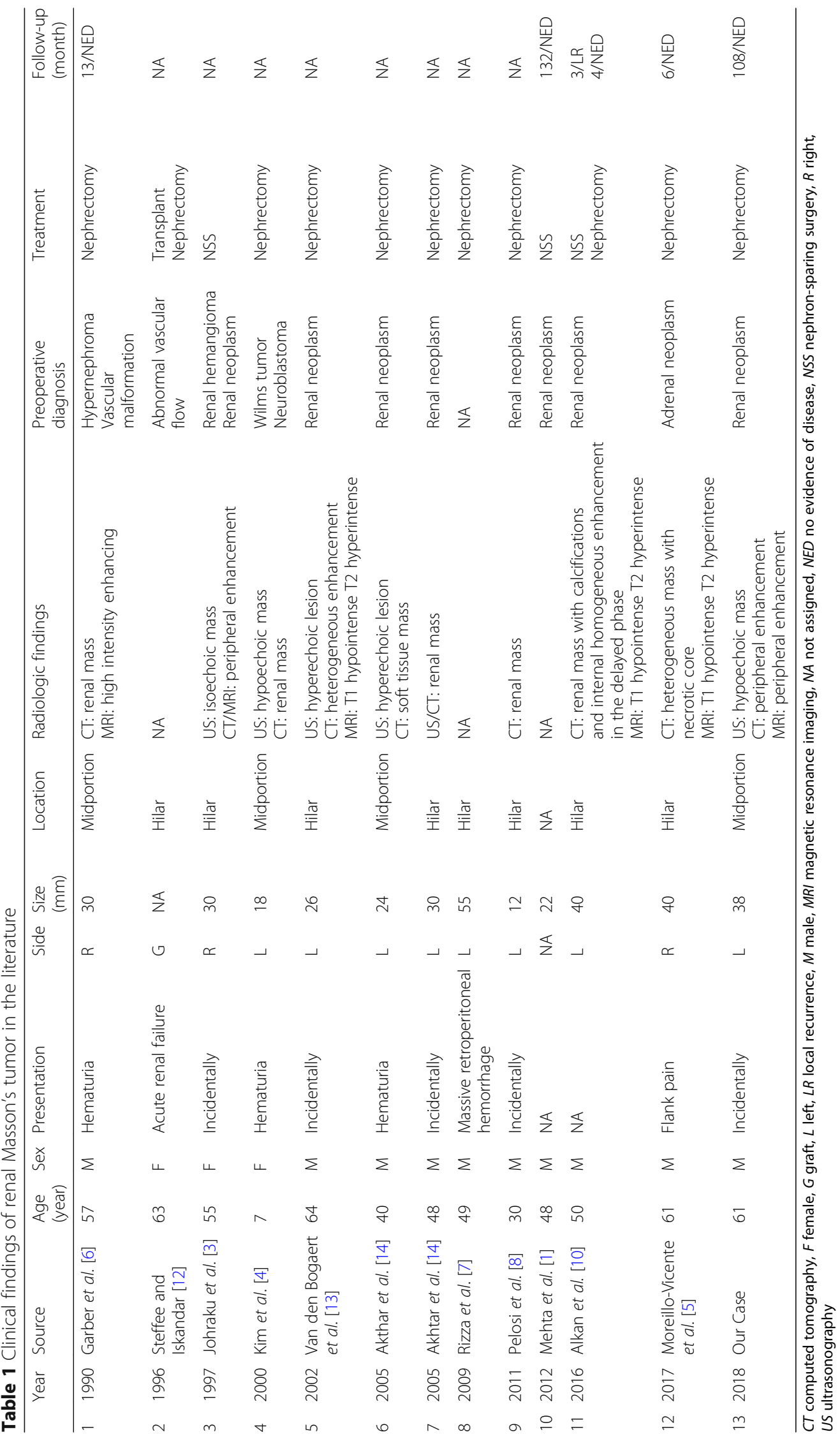


Renal and vesicoprostatic ultrasound found a nonvascularized cystic formation with a thickened and irregular wall on his left kidney.

An abdominal computed tomography (CT) scan revealed a $38 \mathrm{~mm}$ left renal mid-pole lesion, isodense to the renal parenchyma. Dynamic CT showed an early intense and peripheral enhancement and nonenhanced central zone even in the delayed phase (Fig. 1). The renal artery and vein appeared normal. No metastases were demonstrated. We also recovered a CT realized 6 years ago in the surgery department, which illustrated the same lesion but $10 \mathrm{~mm}$ smaller (Fig. 1). For further characterization of the cyst, a magnetic resonance imaging (MRI) was performed. It revealed a lesion with thickened and irregular wall (from 3 to $10 \mathrm{~mm}$ ) isointense on T1-weighted images and hypointense on T2- weighted images with intense enhancement. The central zone was hypointense on $\mathrm{T} 1$ and hyperintense on T2 with no enhancement (Fig. 2). Radiological findings concluded a Bosniak IV cyst. As this cyst type is considered clearly malignant, our patient was accordingly scheduled for surgery. A partial nephrectomy was considered technically difficult for this lesion, so he underwent an open left radical nephrectomy. His postoperative course was uneventful.

On gross examination, cut sections divulged a welldefined medio-renal hemorrhagic and brownish mass measuring $3 \times 2.5 \mathrm{~cm}$. Histological examination of the mass showed a mesenchymal proliferation arising from the wall of a large vessel and developing within its lumen. It was composed of hyalinized papillary and anastomosing channel-like structures that were lined by flat to plump endothelial cells with no atypia or mitotic activity (Fig. 3). An immunohistochemical study revealed diffuse staining of tumors cells for CD-31 and negativity for HMB-45 and cytokeratin (Fig. 3). The diagnosis of IPEH was retained. He was asymptomatic and no recurrence of the tumor has been detected during 9 years of regular clinical and radiological follow-up. Additional file 1 presents a timeline of the case.

\section{Discussion}

Our case showed a Masson's tumor of the kidney that presented as a suspicious cyst, with a slow growth over 6 years and 9 years of follow-up without recurrence. This is only the 12th renal case described in the literature (Table 1).

IPEH is a rare peculiar entity characterized by exuberant endothelial proliferation within the lumen of blood vessels [1]. Even though the precise etiology and physiopathology of IPEH remains undetermined and incompletely understood, many authors suggested that it could be linked to an alteration in the thrombosis process, due to an unusual thrombus organization [2]. Three types of IPEH have been defined: primary or pure type arising from dilated vessels; secondary or mixed type developing in pre-existing vascular lesions such as hemangioma; and third or extravascular type originating from hematomas [1]. In the kidney, IPEH can occur within vessels at many levels: the renal vein, the renal sinus, or the renal parenchyma per se [1]. IPEH has a frequent association with thrombus [2], but not in our case or in three others $[1,3,4]$.

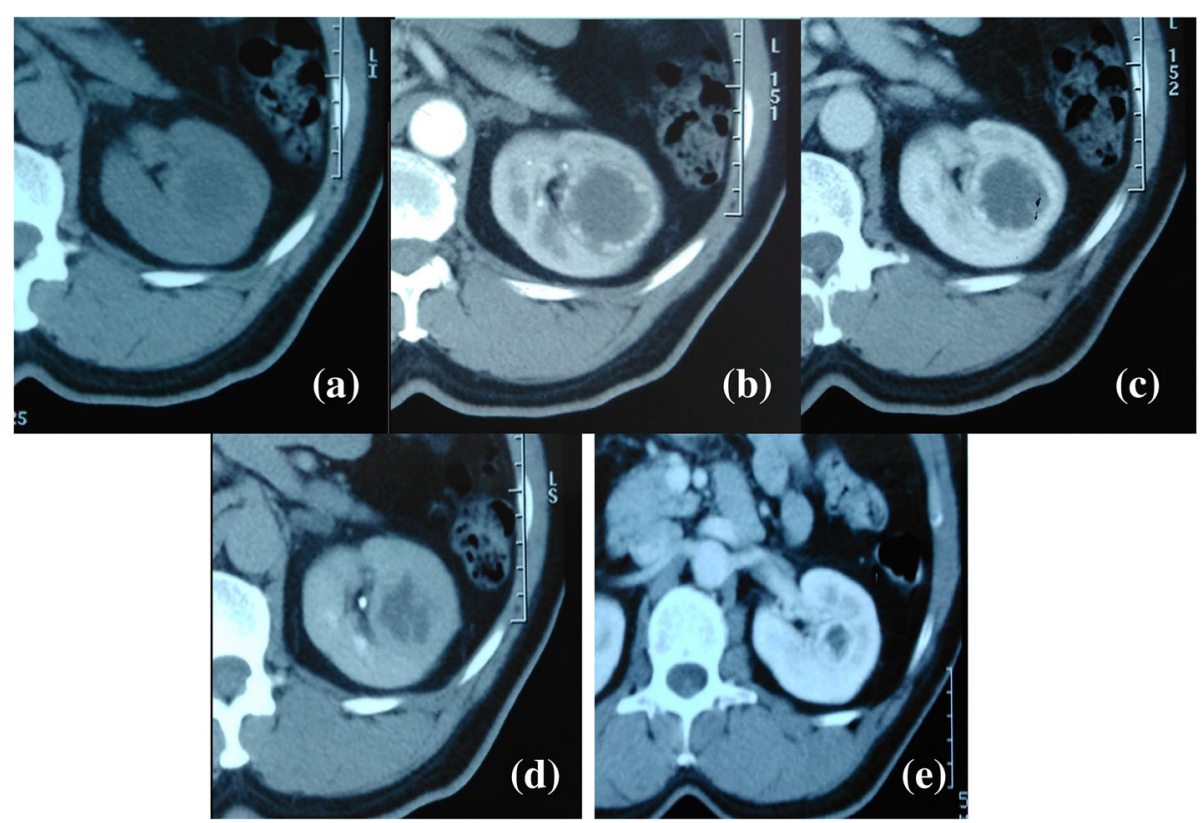

Fig. 1 Computed tomography axial view of the tumor shows intense peripheral enhancement. a Non-enhanced computed tomography. b Arterial phase. c Portal phase. d Delayed phase. e The same lesion, 6 years ago 


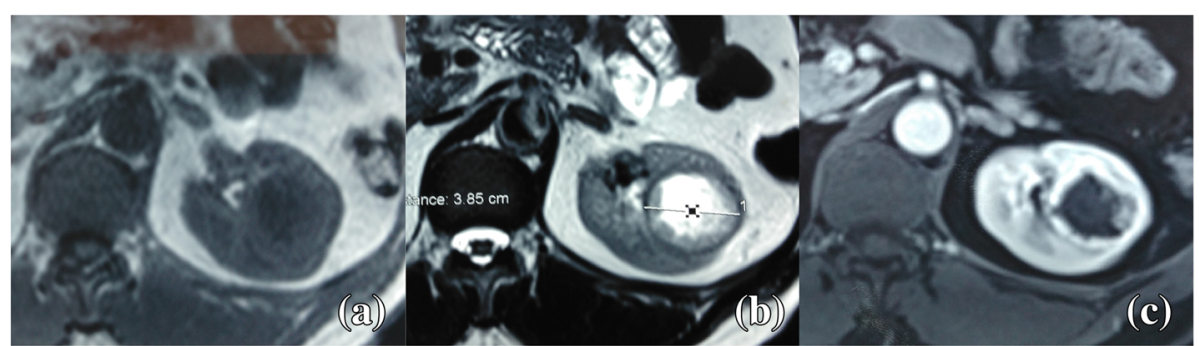

Fig. 2 Magnetic resonance imaging axial view shows a hypointense mass on T1 (a) and hyperintense on T2 (b) with intense peripheral enhancement (c)

IPEH was mainly reported in the extremities skin and soft tissues. Solid organs have been rarely involved [5]. The first renal case was described by Garber et al. [6] in 1990 as a new renal lesion. IPEH generally occur at any age and most often in female patients [5]; however, a renal location seems to be involved more frequently in adult males than females (Table 1). Two cases were reported in patients with chronic kidney failure [7, 8]. The clinical manifestation of this tumor is not specific and varies widely. It can produce, as any other renal mass, flank pain, hematuria, or massive retroperitoneal hemorrhage or it can be asymptomatic and fortuitously diagnosed, as in our case. Lesion size ranges from 18 to $55 \mathrm{~mm}$ and is mostly localized in the left kidney.

In soft tissues, ultrasound shows typically a hypoechoic lesion and dynamic CT shows high peripheral enhancement of the lesion [9]. In the kidney, radiological features are non-specific to differentiate IPEH from other suspicious renal masses. However, in all cases, Masson's tumor is located in the renal hilum or in the midportion of the kidney (Table 1), which should be considered in the diagnoses.

Preoperative diagnosis of renal IPEH was hard to carry out and this led to nephrectomy in all cases. It was managed by a partial nephrectomy as mentioned in three

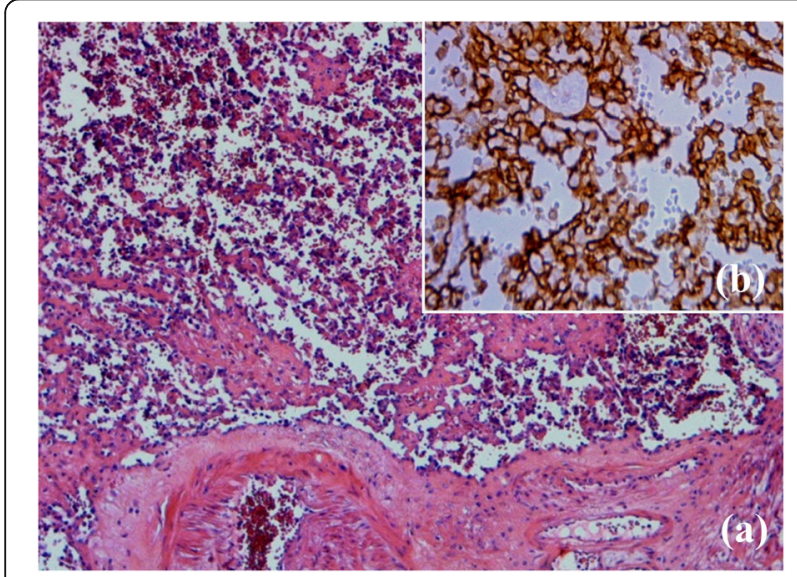

Fig. 3 a The tumor composed of papillary and anastomosing channel-like structures (hematoxylin and eosin $\times 100$ ). b Diffuse staining for CD31 (immunohistochemical $\times 200$ ) cases $[1,3,10]$. In other cases, radical nephrectomy was realized since tumors were located in the renal hilum.

Through Table 1, we can see that some features could evoke the diagnosis of renal IPEH. In that case, a lesion biopsy should be realized and the kidney could be spared. In our case, first, even though the slow growth of the tumor suggested a benign lesion, our decision to proceed in surgery was influenced by the radiological findings that indicated a Bosniak IV cyst, which is malignant in more than $90 \%$ of cases [11]. Second, we did not consider a biopsy because it was not recommended for cystic masses in the guidelines of that time [11].

Finally, neither metastases nor malignant degeneration has been reported with renal IPEH. There is only one case of recurrence, which occurred after a nephron-sparing surgery [10].

\section{Conclusions}

Masson's tumor is a benign vascular degeneration. A renal localization for Masson's tumor could barely be found in the literature. Preoperative diagnosis can be a real challenge. Nephrectomy was realized in all cases because of this entity's non-specific radiological characteristics among suspicious renal masses.

Our case showed that Masson's tumor can present as a suspicious renal cyst, an aspect that was not previously described in the few cases reporting this process in the kidney, and our literature review confirms that some features might evoke the diagnosis. Thus, this entity should be considered more often in the thick of the diagnostic possibilities in order to avoid unnecessary nephrectomies.

\section{Additional file}

Additional file 1: Timeline of the case. (DOCX $14 \mathrm{~kb}$ )

Abbreviations

CT: Computed tomography; IPEH: Intravascular papillary endothelial hyperplasia; MRI: Magnetic resonance imaging

Acknowledgements Not applicable. 


\section{Funding}

This research did not receive any specific grant from funding agencies in the public, commercial, or not-for-profit sectors.

\section{Availability of data and materials}

All data generated or analyzed during this study are included in this published article.

\section{Authors' contributions}

MAE, conception and design of the study, analysis and interpretation of data, drafting the article, and revision and final approval of the version to be submitted. Abo, conception and design of the study, analysis and interpretation of data, drafting the article, and revision and final approval of the version to be submitted. ABI, histopathological analysis and interpretation of data, drafting the article, and revision and final approval of the version to be submitted. MG, acquisition of data, and revision and final approval of the version to be submitted. MCha, conception and design of the study, analysis and interpretation of data, and revision and final approval of the version to be submitted. ABM, radiological analysis and interpretation of data. HA conception and design of the study, analysis and interpretation of data, and revision and final approval of the version to be submitted. MCher, conception and design of the study, analysis and interpretation of data, and revision and final approval of the version to be submitted. MRBS, surgical performance, and revision and final approval of the version to be submitted. AD, conception and design of the study, analysis and interpretation of data, and revision and final approval of the version to be submitted. MCheb, revision and final approval of the version to be submitted. All authors read and approved the final manuscript.

\section{Ethics approval and consent to participate}

Ethical approval was not applicable for the case report. Written consent was obtained from the patient to participate in this case report.

\section{Consent for publication}

Written informed consent was obtained from the patient for publication of this case report and any accompanying images. A copy of the written consent is available for review by the Editor-in-Chief of this journal.

\section{Competing interests}

The authors declare that they have no competing interests.

\section{Publisher's Note}

Springer Nature remains neutral with regard to jurisdictional claims in published maps and institutional affiliations.

\section{Author details}

'Department of Urology, Charles Nicolle University Hospital of Tunis, Boulevard du 9 Avril 1938, 1006 Tunis, Tunisia. ${ }^{2}$ Department of Pathology, Charles Nicolle University Hospital of Tunis, Tunis, Tunisia. ${ }^{3}$ Department of Radiology, Charles Nicolle University Hospital of Tunis, Tunis, Tunisia.

Received: 3 July 2018 Accepted: 26 October 2018

Published online: 22 December 2018

\section{References}

1. Mehta V, Ananthanarayanan V, Antic T, Krausz T, Milner J, Venkataraman G, et al. Primary benign vascular tumors and tumorlike lesions of the kidney: a clinicopathologic analysis of 15 cases. Virchows Arch. 2012;461(6):669-76.

2. Akdur NC, Donmez M, Gozel S, Ustun H, Hucumenoglu S. Intravascular papillary endothelial hyperplasia: histomorphological and immunohistochemical features. Diagn Pathol. 2013;8:167.

3. Johraku A, Miyanaga N, Sekido N, Ikeda H, Michishita N, Saida Y, et al. A case of intravascular papillary endothelial hyperplasia (Masson's tumor) arising from renal sinus. Jpn J Clin Oncol. 1997;27:433-6.

4. Kim HS, Park EJ, Lee JH, Nam JH, Lee MC, Park CS, et al. Intravascular papillary endothelial hyperplasia in the kidney of a child. Virchows Arch. 2000:436:398-400.

5. Moreillo-Vicente L, Gimenez-Bachs JM, Agusti-Martinez A, Salinas-Sanchez AS. Intravascular Papillary Endothelial Hyperplasia: Regarding a Case. Ann Clin Case Rep. 2017;2:1319.
6. Garber BB, Prestipino AJ, Pollack HM, Levine SR, Whitmore KE. Masson's tumor of the kidney: a new renal lesion. J Urol. 1990;143:344-6.

7. Rizza V, Coletti G, Di Cocco P, Mazzotta C, Famulari A, Pisani F. Serious renal hemorrhage in Masson tumor. Transplant Proc. 2009:41(4):1402-4.

8. Pelosi G, Sonzogni A, Viale G. Intravascular papillary endothelial hyperplasia of the renal vein. Int J Surg Pathol. 2011;19(4):518-20.

9. Craig KA, Escobar E, Inwards CY, Kransdorf MJ. Imaging characteristics of intravascular papillary endothelial hyperplasia. Skelet Radiol. 2016;45(11): 1467-72.

10. Alkan E, Sağlıcan Y, Özkanlı AO, Balbay MD. The first recurrent intravascular papillary endothelial hyperplasia (Masson's tumor) of the kidney. Turk J Urol. 2016:42(3):202-5.

11. Long JA, Neuzillet $Y$, Correas JM, de Fromont $M$, Lang $H$, Mejean A, et al. Atypical cysts and cystic tumours of the kidney: histological, radiological and surgical considerations. Conclusions of the AFU 2007 forum. Prog Urol. 2009;19(1):8-14.

12. Steffee C, Iskandar S. Intravascular papillary endothelial hyperplasia in a thrombosed renal allograft vein. Hum Pathol. 1996;27(9):986-9.

13. Van den Bogaert S, Boel K, van Poppel H, Oyen R, Van Damme B. Masson's tumour of the kidney. Cancer Imaging. 2002;2:116-9.

14. Akhtar M, Aslam M, Al-Mana H, Bamefleh H, Al-Khateeb SS, Lindstedt E. Intravascular papillary endothelial hyperplasia of renal vein: report of 2 cases. Arch Pathol Lab Med. 2005;129(4):516-9.

\section{Ready to submit your research? Choose BMC and benefit from:}

- fast, convenient online submission

- thorough peer review by experienced researchers in your field

- rapid publication on acceptance

- support for research data, including large and complex data types

- gold Open Access which fosters wider collaboration and increased citations

- maximum visibility for your research: over $100 \mathrm{M}$ website views per year

At BMC, research is always in progress.

Learn more biomedcentral.com/submissions 